\title{
Mechanism of transmethylation in anisole decomposition over HZSM-5: Experimental study
}

(1) Jiajun Zhang ${ }^{\mathrm{a}, \mathrm{b}}$, Beatriz Fidalgo ${ }^{\mathrm{b}}$, Dekui Shen ${ }^{\mathrm{a},{ }^{*},}$, Rui Xiao ${ }^{\mathrm{a}}$, Sai Gu ${ }^{\mathrm{c}}$

${ }^{a}$ Key Laboratory of Energy Thermal Conversion and Control of Ministry of Education, Southeast University, Nanjing, China

${ }^{\mathrm{b}}$ School of Water, Energy and Environment, Cranfield University, Cranfield, United Kingdom

${ }^{\mathrm{c}}$ Faculty of Engineering and Physical Sciences, University of Surrey, Surrey, United Kingdom

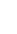

Abstract: This work investigated the decomposition of anisole (methoxyl-based lignin model compound) in a fluidized bed reactor over no catalysts and a series of HZSM-5 zeolite catalysts with different $\mathrm{Si} / \mathrm{Al}$ atomic ratios. Transmethylation reaction was identified as the initial step of the thermal decomposition of anisole, leading to the prominent production of phenolic compounds. Methyl phenols were identified as the main products, with the yield of $o$-cresol being higher than that of $p$-cresol at the temperatures below $600^{\circ} \mathrm{C}$. The transmethylation reaction over HZSM-5 zeolite catalyst was found to occur at temperatures $150^{\circ} \mathrm{C}$ lower than those for non-catalytic reaction, with the yield of the phenolic compounds being promoted by 2.5 times. Production of the main phenolic compounds during the catalytic decomposition of anisole was enhanced to different extents depending on the Si/Al ratio. The highest selectivity of 79 wt. \% was achieved over the zeolite catalyst with a Si/Al ratio of 80 . The Brønsted acid sites of the catalyst played a significant role in both the preferential formation of phenolic compounds and preservation of the methyl group.

Key words: mechanism; anisole; transmethylation; phenolic compounds; Brønsted acid; catalytic decomposition 
- Catalytic decomposition of anisole was investigated with regard to liquid products.

29 - Catalyst preserves more methyl groups on the compounds.

30

- Mechanism for non-catalytic and catalytic transmethylation was proposed.

31

- Major methyl transfer orientations were $o$ - and $p$-positions on a phenolic molecule.

32

33

34 


\section{Introduction}

Renewable energy has attracted tremendous interests due to its potential in alleviating energy supply risk and climate change[1]. In particular biomass resources have been identified as adequate feedstock for the synthesis of fuels and chemicals which are not hazardous to the environment[2]. Lignin, one of the three main components in lignocellulosic biomass, has drawn increasing attention in recent years as the major aromatic source of the bio-based economy[2-7]. Pyrolysis of lignin coupling with catalytic reforming of the bio-oil precursors vapours to produce aromatic hydrocarbons is a promising approach to realise effective utilisation of biomass[8]. Fast pyrolysis of lignin and bio-oil upgrading have been intensively studied[9-14]. However, the complex composition of the primary liquid products derived from the fast pyrolysis of lignin requires further studies in order to accurately establish the reaction pathways followed by each compound and oxygen functionality.

Bio-oil from lignocellulosic biomass has abundant compounds containing methoxy functional group (anisole, guaiacol, syringol and their derivatives). These compounds decompose into phenolics (Ph) and aromatic hydrocarbons ( $\mathrm{AH}$ ) compounds both in-situ during the fast pyrolysis process and ex-situ in subsequent catalytic reforming process. Since the methoxy group is the only functionality of the molecule, anisole (or methoxybenzene) is used as prototype model compound to investigate the reactivity of methoxyl-based compounds present in the liquids from fast pyrolysis of lignin[15]. Most of the existed research on anisole decomposition is focused on reducing coke generation and the deoxygenation process of the phenyl-oxygen bond[16-19]. Open literature about transmethylation as reaction occurring prior to deoxygenation is less extensive, and its mechanism is unclear despite it is essential to understand the entire process of anisole decomposition[20]. Transmethylation is a disproportionation reaction which involves the intramolecular (or intermolecular) transfer of a methyl group cleavage. In the case of anisole decomposition at 
relatively low temperatures, transmethylation is considered to be primary reaction aiding the subsequent formation of aromatic hydrocarbons[21-25]. The combined function of Brønsted and Lewis acid sites is usually considered to promote the transmethylation process $[21,26,27]$. Zeolites present abundantly and well-dispersed surface acid sites and are widely used as catalyst supports for organic compounds decomposition. In fact, the catalytic performance of zeolites on the conversion of lignin-related compounds from biomass to aromatic hydrocarbons and phenolic compounds during pyrolysis has been reported[28-35]. Due to its unique structure and content of acid sites, HZSM-5 has been described as one of the best zeolite catalysts in order to achieve high conversion and selectivity to aromatic hydrocarbons[16,28,29].

The aim of this work is to investigate the primary steps of the reaction mechanism of noncatalytic and catalytic decomposition of anisole, and to address the differences between both processes. The decomposition of anisole was carried out in a fluidised bed reactor, and HZSM-5 zeolite was used as catalyst. In order to address the effect of the acid sites on the catalytic decomposition, the performance of a series of HZSM-5 zeolite catalysts with different Si/Al atomic ratio was studied. The distribution of products in the liquid fraction, with particular focus on the phenolic compounds, was evaluated in order to explain the catalytic activity of the HZSM-5 zeolite on the transmethylation process compared to the non-catalytic reaction. In addition, changes in coke deposition were investigated.

\section{Materials and methods}

\subsection{Materials}

Pure anisole was used as reactant and supplied by Aladdin Reagents Co., Ltd. The silica sand used as inert material of the fluidised bed was purchased from Kermel Laboratory Equipment Co., Ltd, China. The HZSM-5 zeolite catalyst with different Si/Al atomic ratios in composition (i.e. $25,50,80$, and 200 ) was provided by Nankai University Catalyst Co., Ltd, 
China. The HZSM-5 catalysts were labelled as $\mathrm{HZ}(25), \mathrm{HZ}(50), \mathrm{HZ}(80)$ and $\mathrm{HZ}(200)$, respectively. Before being used in the experiments, the catalyst samples were calcined in a muffle furnace at $500^{\circ} \mathrm{C}$ for 3 hours, and subsequently crushed and sieved to a particle size range between 0.18 and $0.25 \mathrm{~mm}$. The surface acidity of the HZSM-5 zeolites was characterized by infrared study of the pyridine absorbed on the catalysts by using a PerkinElmer Frontier FT-IR spectrometer.

\subsection{Methods}

Non-catalytic and catalytic anisole decomposition experiments were carried out in the bench scale fluidised bed reactor $\left(D^{*} H(m m)=32 * 600\right)$ sketched in Fig.1. Nitrogen was used as fluidising gas. The minimum fluidisation velocity $\left(U_{m f}\right)$ was determined by means of Eq. 1[36], and was $0.043 \mathrm{~m} / \mathrm{s}$ for the experiments performed with only zeolite catalyst and $0.062 \mathrm{~m} / \mathrm{s}$ for the experiments with no catalyst (only silica sand). Actual experimental flow velocity was adjusted by running cold experiments, and set to approximately two times the $\mathrm{U}_{\mathrm{mf}}$.

$$
U_{m f}=\frac{\left(\psi d_{p}\right)^{2}}{150 \mu}\left[g\left(\rho_{g}-\rho_{g}\right)\right] \frac{\varepsilon_{m f}^{3}}{1-\varepsilon_{m f}}
$$

Eq. 1

where $U_{m f}$ is the minimum fluidisation velocity $(\mathrm{m} / \mathrm{s}), \psi$ is the particle sphericity (1 was adopted in the calculation for an ideal sphericity), $d_{p}$ is the particle diameter $(\mathrm{m}), \mu$ is the gas viscosity $(\mathrm{kg} / \mathrm{m} \cdot \mathrm{s}), g$ is gravitational acceleration $9.81 \mathrm{~m} / \mathrm{s}^{2}, \rho_{c}$ and $\rho_{g}$ are the densities of particle and gas respectively $\left(\mathrm{kg} / \mathrm{m}^{3}\right)$, and $\varepsilon_{m f}$ is porosity at the minimum fluidisation velocity. Non-catalytic experiments were performed at temperatures between $500^{\circ} \mathrm{C}$ to $800^{\circ} \mathrm{C}$, with increasing intervals of $50^{\circ} \mathrm{C} .50 \mathrm{~g}$ of silica sand $\left(\mathrm{SiO}_{2}\right)$ were placed inside the reactor and fluidised by a $\mathrm{N}_{2}$ flow rate of $360 \mathrm{~L} / \mathrm{h}$. The amount of sand was set from preliminary experiments in order to ensure adequate contact between the anisole and bed material. A total amount of $8.3 \mathrm{~g}$ of liquid anisole was place in a syringe pump at the beginning of the experiment and pumped into the reactor at a constant flow rate of $50 \mathrm{~g} / \mathrm{h}$. Reaction time 
was $10 \mathrm{~min}$. Catalytic decomposition experiments were carried out in a temperature range between $200^{\circ} \mathrm{C}$ and $800^{\circ} \mathrm{C}$, with increasing intervals of $100^{\circ} \mathrm{C} .50 \mathrm{~g}$ of fresh pre-calcined HZSM-5 catalyst with a Si/Al ratio of $25, \mathrm{HZ}(25)$, were placed inside the reactor and fluidised by a $\mathrm{N}_{2}$ flow rate of $240 \mathrm{~L} / \mathrm{h}$ (no inert sand was added). Anisole flow rate and reaction time were similar to those for the non-catalytic experiments. The effect of the catalyst acidity on the anisole conversion was investigated at $400^{\circ} \mathrm{C}$ by testing $\mathrm{HZSM}-5$ with different Si/Al atomic ratios in composition, i.e. $25,50,80$, and $200 . \mathrm{N}_{2}$ flow rate, anisole flow rate, and reaction time were $240 \mathrm{~L} / \mathrm{h}, 50 \mathrm{~g} / \mathrm{h}$, and $10 \mathrm{~min}$, respectively. For all the experiments, the outflow stream was passed through a three stages ethanol quench traps in order to collect the liquid product, and the sample was diluted to a constant volume of $150 \mathrm{ml}$ after each experiment. The liquid fraction was then analysed by GC-MS in an Agilent GC7890 gas chromatograph-mass spectrometer equipped with a capillary column DB-5ms (30 m x 250 $\mu \mathrm{m} \times 0.25 \mu \mathrm{m})$. The injector temperature was kept at $270^{\circ} \mathrm{C}$. The column was programmed from $40^{\circ} \mathrm{C} \mathrm{(3} \mathrm{minutes)} \mathrm{to} 180^{\circ} \mathrm{C}(2 \mathrm{~min})$ with the heating rate of $5^{\circ} \mathrm{C} / \mathrm{min}$, and finally to $280^{\circ} \mathrm{C}$ with the heating rate of $10^{\circ} \mathrm{C} / \mathrm{min}$. Entire running time for each GC-MS test was $45 \mathrm{~min}$. The mass spectra were operated in electron ionization (EI) mode at $70 \mathrm{eV}$, and were obtained from $\mathrm{m} / \mathrm{z} 35-550$. The products were quantified by total ion and were identified based on the database of NIST library, and was calibrated with an external standard. All detected compounds (peak threshold value: 18) were utilised for the calibration. The amount of carbonaceous deposits on the catalyst was determined by thermogravimetric analysis with Setsys Evolution TGA Instrument. Yields of the liquid fraction and carbon deposits were determined as a percentage of the initial weight of the anisole sample. Duplicated experiments and system deviation analysis are shown in the supplementary materials (Table S1 and S2). 


\section{Results and discussion}

134

135

136

137

138

139

140

141

\subsection{Influence of catalyst on the decomposition of anisole}

The conversion of anisole at different temperatures in non-catalytic and catalytic decomposition of anisole is shown in Fig. 2. In both sets of experiments, the anisole conversion values increased with temperature. In the case of non-catalytic experiments, the conversion increased from approximately $30.54 \% \%$ at $200^{\circ} \mathrm{C}$ up to $99.8 \%$ at $650^{\circ} \mathrm{C}$, and remained constant for higher temperatures. It was noticed that little anisole conversion was observed at $400^{\circ} \mathrm{C}$ and below when no catalysts was used, and that the conversion was not towards liquid at temperature $550^{\circ} \mathrm{C}$. In the case of catalytic experiments with catalyst $\mathrm{HZ}(25)$, conversion increased from $73.6 \%$ at $200^{\circ} \mathrm{C}$ to around $99.4 \%$ at $400^{\circ} \mathrm{C}$, which was maintained at higher temperatures. As can be seen, in the presence of the $\mathrm{HZ}(25)$ catalyst, the complete conversion of anisole was achieved at lower temperature than in the case of non-catalytic decomposition. This reflects the catalyst effect in lowering activation energy of reactions.

Fig. 3 (a) and (b) presents the yields of products in the liquid fraction at different temperatures in non-catalytic and catalytic decomposition of anisole. The specific di- and trimethyl-phenols are detailed in Fig. 3 (c) and (d). Table 1 shows the grouped yields of the aromatic hydrocarbons and phenolic compounds for each experiment. Yields of specific $\mathrm{Ph}$ compounds, i.e. phenol and methyl phenols (mono-, di- and trimethyl-phenols) are also summarized.

Both for non-catalytic and catalytic reactions, maximum yield of liquid products was observed at the minimum temperature required for achieving the complete conversion; i.e., $650^{\circ} \mathrm{C}$ for non-catalytic decomposition and $400^{\circ} \mathrm{C}$ for catalytic decomposition. These temperature values are referred as "key temperatures" in this work. Phenolic compounds were the primary products at the key temperature and below. The maximum yield of phenolic compounds was $27.4 \mathrm{wt} . \%$ at $650^{\circ} \mathrm{C}$ in non-catalytic decomposition process (shown 
in Table 1). The yield increased up to 70.0 wt. \% when the $H Z(25)$ was used while the temperature at which this maximum value was obtained decreased in $150^{\circ} \mathrm{C}$ (maximum at $400^{\circ} \mathrm{C}$ ). This reflects the decrease in the activation energy of the reactions producing phenolic compounds when adding the catalyst. Considering particular Ph compounds, only phenol and n-methyl phenols (ortho-cresol and para-cresol) were produced during the noncatalytic decomposition of anisole. Ortho-cresol was first formed at $550^{\circ} \mathrm{C}$, while p-cresol appeared at $600^{\circ} \mathrm{C}$. Yields of both compounds increased with temperature and peaked at $650^{\circ} \mathrm{C}$. Moreover, o-cresol yield was higher than p-cresol yield at $600^{\circ} \mathrm{C}$, while the opposite was observed at $650^{\circ} \mathrm{C}$. In the case of anisole catalytic decomposition, $o$ - and $p$-cresols were also the main compounds in the methyl phenolic fraction. The yield of $o$-cresol and $p$-cresol was promoted by approximately 8 and 7 times respectively when $\mathrm{HZ}(25)$ was used as catalyst. Similar to non-catalytic decomposition, o-cresol yield was higher than that of $\mathrm{p}$ cresol at low temperatures (between 200 and $350^{\circ} \mathrm{C}$ ), while p-cresol yield was larger at 400 and $500^{\circ} \mathrm{C}$. In addition, multi-methyl phenols, such as 2,6-dimethylphenol, 3,4dimethylphenol and 2,4,6-trimethylphenol, were abundantly produced over $\mathrm{Hz}(25)$ at temperatures below the key temperature.

Aromatic compounds dominated over phenolics at temperatures higher than the key temperature. In non-catalytic decomposition process, $\mathrm{AH}$ were present in the whole range of tested temperatures but the maximum yield of $7.3 \mathrm{wt}$ \% was observed at the key temperature of $650^{\circ} \mathrm{C}$. The yield then decreased to $4.9 \mathrm{wt} . \%$ at $800^{\circ} \mathrm{C}$ following the decrease in the liquid product fraction, as high temperatures usually result in increasing gaseous products yield[14]. A significant increment of AH yields was observed at temperatures higher than the key temperature when catalytic decomposition over $\mathrm{HZ}(25)$ was performed (1.9 wt. $\%$ at $400{ }^{\circ} \mathrm{C}$ and $33.5 \mathrm{wt} . \%$ at $\left.600{ }^{\circ} \mathrm{C}\right)$. In this case, the maximum $\mathrm{AH}$ yield was not observed at the key temperature but at a higher temperature of $600{ }^{\circ} \mathrm{C}$. Moreover, maximum $\mathrm{AH}$ yield improved by almost 5 times compared to that obtained from non- 
catalytic experiments. The temperature at which the maximum AH yield was obtained decreased $50{ }^{\circ} \mathrm{C}$ when using a catalyst.

Fig. 4(a) shows the influence of temperature on the deposition of carbon for both noncatalytic decomposition and catalytic decomposition over $\mathrm{HZ}(25)$ of anisole. Carbonaceous deposits yields were higher when catalytic decomposition was conducted because the acid sites on HZSM-5 promote the absorption of anisole and accelerate the reaction rates which in turn results in more carbon deposition[37]. For non-catalytic decomposition, the yield of carbonaceous deposits was found to increase fast with temperature. Interestingly, in the case of catalytic decomposition, the carbon deposits increased up to a maximum at $600{ }^{\circ} \mathrm{C}$, and then decreased at higher temperature. This trend is similar to that followed by the aromatic hydrocarbons, and has been previously reported[34,35,37,38].

The results on liquid and solid yields and liquid product distribution suggest that transmethylation occurs as the main reaction at the range of low temperatures when anisole conversion is not complete either with or without catalyst. Moreover, the formation of aromatic hydrocarbons as non-primary products depends both on temperature and acid catalytic effect, and deoxygenation as secondary step during anisole decomposition requires higher energy to take place. As explained above, complete anisole conversion and maximum yield of $\mathrm{Ph}$ compounds were simultaneously reached at $400{ }^{\circ} \mathrm{C}$ over zeolite $\mathrm{HZ}(25)$. Maximum yield of $\mathrm{AH}$ compounds was observed at $600{ }^{\circ} \mathrm{C}$. In the case of non-catalytic decomposition, although the complete conversion of anisole was attained at $600{ }^{\circ} \mathrm{C}$, maximum yields of both $\mathrm{Ph}$ and $\mathrm{AH}$ compounds were obtained at $650^{\circ} \mathrm{C}$. In other words, the presence of the catalyst lowered the temperature at which Ph yield peaked approximately

$207150{ }^{\circ} \mathrm{C}$, while in the case of maximum yield of $\mathrm{AH}$ compounds the temperature decreased 208 only approximately $50^{\circ} \mathrm{C}$. Indicates that HZSM-5 is better at promoting the transmethylation reaction than the deoxygenation process. Notably, in the catalytic decomposition process, the steep decrease of phenolic compound yields coincided with the sharp increase of $A H$ 
yields, which implies that phenolics are precursor compounds for the formation of AHs. At high temperatures (around $600{ }^{\circ} \mathrm{C}$ and higher) polycondensation of $\mathrm{AH}$ is favoured which can lead to coke deposition. Simultaneously, cracking of macromolecules from polycondensation of $\mathrm{AH}$ over zeolite is enhanced, increasing gas yields and decreasing carbon and liquid yield[14].

\subsection{Influence of the catalyst Si/Al ratio on the decomposition of anisole}

HZSM-5 catalysts with four different Si/Al ratio were tested in order to evaluate the effect of catalyst properties on transmethylation in terms of its acidic properties, i.e. the density, strength, and type of acid sites[39]. Decomposition of anisole over HZSM-5 with Si/Al ratios of $25,50,80$ and 200 was studied at the key temperature of $400^{\circ} \mathrm{C}$, based on the results obtained over $\mathrm{HZ}(25)$ related to the transmethylation reaction. The anisole conversion was approximately $99.5 \%$ in all cases, which exhibits the limited effect of the change in Si/Al ratio on the total conversion. However, slight changes on liquid product yield and distribution were observed at different $\mathrm{Si} / \mathrm{Al}$ ratios (see Table 1 and Fig. 5). As observed in the case of $\mathrm{HZ}(25)$, phenol and $\mathrm{n}$-cresol were major products in the $\mathrm{Ph}$ fraction for all the tested Si/Al ratios. Formation of xylenols (or dimethyl phenols) was also significant. Increasing of Si/Al ratio to 80 promoted Ph products yield from 70 wt. \% to 79 wt. \%. Nevertheless, further increment of Si/Al ratio to 200 resulted in a decrease of the $\mathrm{Ph}$ compound yields to approximately 68 wt. \%, especially for phenol and n-cresol. In the case of n-cresol, p-cresol yield was slightly higher than that of $o$-cresol over $\mathrm{HZ}(25)$. However, the opposite was observed when Si/Al ratio increased. This result points that a decrease in the acid density of the zeolite favoured the preferential attack of ortho-positions because of the lower energy requirement. At $400^{\circ} \mathrm{C}, \mathrm{AH}$ were not major products from anisole catalytic decomposition for any of the tested zeolites. In fact, in the case of $\mathrm{HZ}(80)$ and $\mathrm{HZ}(200)$, AH yields were negligible. Fig. 4(b) shows the yield of carbonaceous deposits at different Si/Al ratios. As can be seen, carbon deposition was also influenced by the acidity of the surface catalyst with a 
minimum value reached over $\mathrm{HZ}(80)$. The trend observed for the yield of carbon deposits was opposite to that observed for the yield of phenolic compounds. Thus, the lowest and highest yield of carbonaceous deposits and phenolic compounds respectively were obtained over the zeolite with $\mathrm{Si} / \mathrm{Al}$ ratio of 80 . Similar result was observed by $\mathrm{Du}$ et al. when producing $\mathrm{AH}$ by catalytic pyrolysis of microalgae with zeolites[40].

It has been reported that the activity and stability of zeolites as catalysts depend on the amount and proportion between Brønsted and Lewis acid sites[41]. Brønsted acid are known to play a vital role in the catalytic transmethylation due to easier group exchange compared to Lewis acid[21]. At the same time, Lewis acid sites have been found to aid catalytic stability due to lower coking rates[41]. In order to properly address the effect of the surface acidity of the zeolite on its catalytic performance, pyridine-FTIR analysis was carried and the acid density distribution of Brønsted and Lewis sites was identified. As can be seen in Table 2, the acid density of the zeolite decreases when the Si/Al ratio increases, which corresponds to the decline of acid sites due to the aluminium dispersion in the silica framework. It is also observed that the amount of Brønsted acid sites is higher than the Lewis acid sites for $\mathrm{HZ}(25)$ and $\mathrm{HZ}(50)$. However, the density of the Brønsted acid sites decreased faster with the Si/Al ratio than that of Lewis acid sites, and consequently Lewis acid sites predominate at high $\mathrm{Si} / \mathrm{Al}$ ratio $(\mathrm{HZ}(80)$ and $\mathrm{HZ}(200))$.

Similar to results previously obtained for the catalytic pyrolysis of microalgae and glucose[32,40], the experiments in this work showed higher Ph yields over $\mathrm{HZ}(80)$ than those over $\mathrm{HZ}(25)$ and $\mathrm{HZ}(50)$. Zeolites with low Si/Al ratios present enhanced initial catalytic performance because of the high surface acid density[39]. However, the presence of large amount of acid sites, particularly strong acid sites as in the case of $\mathrm{HZ}(25)$, also favours the rapid deposition of carbon and subsequent catalyst deactivation due to the blockage of the pore mouth and limited access of reactant and intermediate molecules to the active sites[32,41]. The high $\mathrm{Ph}$ yield obtained over $\mathrm{HZ}(80)$ can be related to its improved catalytic 
stability. Coking rate for $\mathrm{HZ}(80)$ drops compared to that of $\mathrm{HZ}(25)$ and $\mathrm{HZ}(50)$ because of the reduced amount of Brønsted acid sites [41]. Moreover, S. Qu et al [41] reported that when Si/Al increased carbon deposits are more likely to build uniformly in the pore walls instead of plugging the pore-mouth, the rapid deactivation of the catalyst being prevented. On the other hand, the higher $\mathrm{Ph}$ yield obtained over $\mathrm{HZ}(80)$ compared to $\mathrm{HZ}(200)$ may be related to the Lewis to Brønsted acid sites ratio. Although both $\mathrm{HZ}(80)$ and $\mathrm{HZ}(200)$ present low amount of Brønsted acid sites, the former exhibits significantly higher Lewis to Brønsted acid sites ratio. The relatively larger amount of Lewis acid sites in $\mathrm{HZ}(80)$ compared to that in $\mathrm{HZ}(200)$ seems to better promote the formation of the phenolic compounds[41]. Therefore it can be concluded that acid sites with relatively low density and medium strength are preferred for enhancing liquid production and reducing carbon deposition[23,39,41]. Analogous conclusions from investigations of the catalytic activity of zeolites with different Si/Al ratios have been previously stated[42-44].

\subsection{Mechanism of anisole decomposition at "key temperature"}

Fig. 6 shows the proposed mechanisms for the non-catalytic and catalytic decomposition of anisole at the key temperatures. Transmethylation is the main reaction occurring during the process of anisole decomposition at this range of temperatures, as observed from the experimental results on the liquid fraction compositions. In other words, results exhibit that anisole decomposition is initiated via the transmethylation reaction.

In the case of catalytic decomposition (Fig. 6a), a plausible mechanism is that the anisole is first converted into phenol (reaction 1 ) followed by the relocation of the methyl radical to form o-cresol (reaction 2) and p-cresol (reaction 3). At temperatures between 200 and 350 ${ }^{\circ} \mathrm{C}$, the ortho-position transfer is predominant. However, at $400{ }^{\circ} \mathrm{C}$, both ortho- and paraposition transfers are promoted. It can be inferred that the transfer of methyl groups to ortho-position has lower energy costs than that to para-positions since the $o$-cresol was formed at lower temperatures. Moreover, the slight decrease of relative yield of $o$-cresol to 
p-cresol at the key temperature may be attributed to the formation of $o$-toluene via deoxygenation of o-cresol. Interestingly, formation of methyl anisole is observed at the lowest tested temperature, i.e. $200{ }^{\circ} \mathrm{C}$, which indicates that transfer of methyl groups in the anisole molecule is possible before this is largely converted. The addition of another methyl radical to the $n$-cresol molecule gives rise to the formation of xylenols (Reaction 4). This reaction occurs at temperatures of $300{ }^{\circ} \mathrm{C}$ or higher. Ortho-position transfer (positions 2 and 6 of the benzene ring) is favoured over para-position (position 4 of the benzene ring). Metaposition transfer also occurs although to a small extent. In addition, the rearrangement to trimethyl phenols (Reaction 5) is observed to a lesser extent. The larger yields of xylenols indicate that these compounds act as the precursors of the transmethylation transfers for trimethyl-phenol formation. As in the case of cresols and xylenols, the major orientations for transmethylation are the ortho- and para-positions, and are favoured by the increase in temperature.

In the case of the non-catalytic decomposition of anisole (Fig. 6b), the most probable conversion route also involves the formation of phenol (reaction 1 ). Contrary to the catalytic decomposition, the transfer of the methyl radical to form n-cresols (reaction 2 ) is not a significant conversion route. Moreover, the relocation of other methyl radicals to form diand trimethyl phenols does not occur under thermal decomposition conditions. This implies that methyl groups are preserved and transmethylation is favoured in the case of catalytic decomposition due to the acid environment provided by the presence of the catalyst. At temperatures below the key temperature, when thermal decomposition of anisole is not complete, the yield of $\mathrm{AH}$ is in the same order as that for $\mathrm{Ph}$ compounds. This points to the conversion of phenol into benzene (Reaction 3), followed by the formation of toluene (Reaction 4) and ethylbenzene (Reaction 6), which increase with temperature. It is also possible that toluene is produced by cresols through deoxygenation (Reaction5). In addition, 
314 as temperature increases, formation of benzofuran may occur through cyclization with the

315 junction of C-O bond (reaction 7)[45].

\section{Conclusion}

In this work, the non-catalytic and catalytic decomposition of anisole in a fluidized bed was investigated. A series of zeolite HZSM-5 with different $\mathrm{Si} / \mathrm{Al}$ atomic ratios was tested as catalyst. Transmethylation was found to be primary reaction in the decomposition of anisole at low-to-moderate temperatures, leading to the formation of phenolic compounds. Orthocresol and para-cresol were the most abundant substances containing a methyl group in the products. Experimental results indicated that complete conversion of anisole is achieved at $650{ }^{\circ} \mathrm{C}$ in the absence of a catalyst and at $400{ }^{\circ} \mathrm{C}$ in the presence of HZSM-5. The presence of the catalysts reduced the energy cost by aiding a decrease in the temperature for transmethylation of $150^{\circ} \mathrm{C}$, promoting the transmethylation process, and increasing in the yield of phenolic compounds by 2.5 times. Reaction mechanisms for non-catalytic and

327 catalytic decomposition at key temperatures were proposed to explain the main conversion pathways of anisole and other intermediate products. In the case of the catalytic decomposition of anisole, acidity of the catalyst contributed to preserve methyl groups and resulted in larger selectivity towards compounds containing methyl functionality. This was particularly remarkable in the case of multi-methyl phenolic products whose formation was only observed in the presence the zeolite catalyst. In the case of catalytic decomposition of anisole, the highest yield of phenolic compounds was observed over HZSM-5 with a Si/Al ratio of 80 . The enhanced anisole conversion and reduced coking rate exhibited by $\mathrm{HZ}(80)$ resulted in improved catalytic stability.

\section{Author information}




\section{Author Contributions}

341 All authors have given approval to the final version of the manuscript.

\section{Notes}

343 The authors declare no competing financial interest.

344

\section{Acknowledgement}

The authors would like to acknowledge financial support from the National Natural Science Foundation of China (project reference: 51476034, 51525601 and 51628601), Natural Science Foundation of Jiangsu Province (project reference: BK20161423), and the FP7 Marie Curie iComFluid (project reference: 312261).

\section{References}

[1] B.J.M. de Vries, D.P. van Vuuren, M.M. Hoogwijk, Renewable energy sources: Their global potential for the first-half of the 21st century at a global level: An integrated approach, Energy Policy. 35 (2007) 2590-2610. doi:10.1016/j.enpol.2006.09.002.

[2] M. He, Y. Sun, B. Han, Green Carbon Science: Scientific Basis for Integrating Carbon Resource Processing, Utilization, and Recycling, Angew. Chemie Int. Ed. 52 (2013) 9620-9633. doi:10.1002/anie.201209384.

[3] J. He, C. Zhao, J. a. Lercher, Ni-catalyzed cleavage of aryl ethers in the aqueous phase, J. Am. Chem. Soc. 134 (2012) 20768-20775. doi:10.1021/ja309915e.

[4] J. Cornella, R. Martin, Metal-catalyzed activation of ethers via C -0 bond cleavage : a new strategy for molecular diversity, Chem. Soc. Rev. 43 (2014) 8081-8097. doi:10.1039/C4CS00206G.

[5] L. Zhang, R. Liu, R. Yin, Y. Mei, Upgrading of bio-oil from biomass fast pyrolysis in China: A review, Renew. Sustain. Energy Rev. 24 (2013) 66-72. 
doi:10.1016/j.rser.2013.03.027.

365 [6] M. Saidi, F. Samimi, D. Karimipourfard, T. Nimmanwudipong, B.C. Gates, M.R. Rahimpour, Upgrading of lignin-derived bio-oils by catalytic hydrodeoxygenation, Energy Environ. Sci. 7 (2014) 103-129. doi:10.1039/C3EE43081B.

[7] S. Van den Bosch, W. Schutyser, R. Vanholme, T. Driessen, S.-F. Koelewijn, T. Renders, Green Chem. 12 (2010) 1493-1513. doi:10.1039/c004654j.

[9] P. Chantal, S. Kaliaguine, J.L. Grandmaison, A. Mahay, Production of hydrocarbons from aspen poplar pyrolytic oils over H-ZSM5, Appl. Catal. 10 (1984) 317-332. doi:10.1016/0166-9834(84)80127-X.

[10] J.D. Adjaye, N.N. Bakhshi, Catalytic conversion of a biomass-derived oil to fuels and chemicals I: Model compound studies and reaction pathways, Biomass Bioenergy. 8 (1995) 131-149. doi:10.1016/0961-9534(95)00018-3.

[11] M.C. Samolada, a. Papafotica, I. a. Vasalos, C. Samolada M, a. Papafotica, A. Vasalos I, Catalyst evaluation for catalytic biomass pyrolysis, Energy and Fuels. 14 (2000) 1161-1167. doi:10.1021/ef000026b.

[12] A.G. Gayubo, A.T. Aguayo, A. Atutxa, R. Aguado, M. Olazar, J. Bilbao, Transformation of Oxygenate Components of Biomass Pyrolysis Oil on a HZSM-5 Zeolite. II. Aldehydes, Ketones, and Acids, Ind. Eng. Chem. Res. 43 (2004) 2619-2626. doi:10.1021/ie030792g. 
[13] J. Adam, E. Antonakou, A. Lappas, M. Stöcker, M.H. Nilsen, A. Bouzga, J.E. Hustad, G. $\varnothing y e$, In situ catalytic upgrading of biomass derived fast pyrolysis vapours in a fixed bed reactor using mesoporous materials, Microporous Mesoporous Mater. 96 (2006) 93-101. doi:10.1016/j.micromeso.2006.06.021.

[14] D.K. Shen, S. Gu, K.H. Luo, S.R. Wang, M.X. Fang, The pyrolytic degradation of woodderived lignin from pulping process, Bioresour. Technol. 101 (2010) 6136-6146. doi:10.1016/j.biortech.2010.02.078.

[15] S.J. Hurff, M.T. Klein, Reaction pathway analysis of thermal and catalytic lignin fragmentation by use of model compounds, Ind. Eng. Chem. Fundam. 22 (1983) 426430. doi:10.1021/i100012a012.

[16] R. Thilakaratne, J.-P. Tessonnier, R.C. Brown, T. Jean-Philippe, R.C. Brown, Conversion of methoxy and hydroxyl functionalities of phenolic monomers over zeolites, Green Chem. 18 (2016) 2231-2239. doi:10.1039/C5GC02548F.

[17] S. Pichaikaran, P. Arumugam, Vapour phase hydrodeoxygenation of anisole over ruthenium and nickel supported mesoporous aluminosilicate, Green Chem. 18 (2016) 2888-2899. doi:10.1039/C5GC01854D.

[18] Q. Lu, C.-J. Chen, W. Luc, J.G. Chen, A. Bhan, F. Jiao, Ordered Mesoporous Metal Carbides with Enhanced Anisole Hydrodeoxygenation Selectivity, ACS Catal. 6 (2016) 3506-3514. doi:10.1021/acscatal.6b00303.

[19] M. Tobisu, T. Takahira, N. Chatani, Nickel-Catalyzed Cross-Coupling of Anisoles with Alkyl Grignard Reagents via C-O Bond Cleavage, Org. Lett. 17 (2015) 4352-4355. doi:10.1021/acs.orglett.5b02200.

[20] N. Ballarini, F. Cavani, L. Maselli, A. Montaletti, S. Passeri, D. Scagliarini, C. Flego, C. Perego, The transformations involving methanol in the acid- and base-catalyzed gasphase methylation of phenol, J. Catal. 251 (2007) 423-436. 
doi:10.1016/j.jcat.2007.07.033.

414 [21] Q. Meng, H. Fan, H. Liu, H. Zhou, Z. He, Z. Jiang, T. Wu, B. Han, Efficient Transformation of Anisole into Methylated Phenols over High-Silica HY Zeolites under

[22] T. Prasomsri, A.T. To, S. Crossley, W.E. Alvarez, D.E. Resasco, Catalytic conversion of anisole over $\mathrm{HY}$ and $\mathrm{HZSM}-5$ zeolites in the presence of different hydrocarbon mixtures, Appl. Catal. B Environ. 106 (2011) 204-211. doi:10.1016/j.apcatb.2011.05.026.

[23] K. Wang, X. Dong, Z. Chen, Y. He, Y. Xu, Z. Liu, Highly selective synthesis of para-cresol by conversion of anisole on ZSM-5 zeolites, Microporous Mesoporous Mater. 185 (2014) 61-65. doi:10.1016/j.micromeso.2013.11.007.

[24] J. Cornella, E. Gómez-Bengoa, R. Martin, Combined experimental and theoretical study on the reductive cleavage of inert C-O bonds with silanes: Ruling out a classical $\mathrm{Ni}(0) / \mathrm{Ni}(\mathrm{II})$ catalytic couple and evidence for $\mathrm{Ni}(\mathrm{I})$ intermediates, J. Am. Chem. Soc. 135 (2013) 1997-2009. doi:10.1021/ja311940s.

[25] C. Mackie, R. Doolan, F. Nelson, kinetics of the thermal decomposition of methoxybenzene(anisole), J. Phys. Chem. C. 93 (1989) 664-670.

[26] M.E. Sad, C.L. Padró, C.R. Apesteguía, Synthesis of cresols by alkylation of phenol with methanol on solid acids, Catal. Today. 133-135 (2008) 720-728. doi:10.1016/j.cattod.2007.12.074.

[27] M.E. Sad, C.L. Padró, C.R. Apesteguía, Study of the phenol methylation mechanism on zeolites HBEA, HZSM5 and HMCM22, J. Mol. Catal. A Chem. 327 (2010) 63-72. doi:10.1016/j.molcata.2010.05.014.

M. Guisnet and J. P. Gilson, Zeolites for Cleaner Technologies, Imperial College Press, 
2002.

[29] S. Ivanova, B. Louis, B. Madani, J.P. Tessonnier, M.J. Ledoux, C. Pham-Huu, ZSM-5 coatings on-SiC monoliths: Possible new structured catalyst for the methanol-toolefins process, J. Phys. Chem. C. 111 (2007) 4368-4374. doi:10.1021/jp067535k.

[30] G.W. Huber, G.W. Huber, M. Amherst, Y. Cheng, J. Jae, J. Shi, W. Fan, Y. Cheng, J. Jae, J. Shi, W. Fan, G.W. Huber, Catalytic Fast Pyrolysis of Lignocellulosic Biomass with Bifunctional Ga / ZSM-5 Catalysts Catalysts, (2012). doi:10.1002/ange.201107390.

[31] M.T. Blatnik, Optimization of mixing in a simulated biomass bed reactor with a center feeding tube, University of Massachusetts Amherst, 2013.

[32] A.J. Foster, J. Jae, Y.-T.T. Cheng, G.W. Huber, R.F. Lobo, Optimizing the aromatic yield and distribution from catalytic fast pyrolysis of biomass over ZSM-5, Appl. Catal. A Gen. 423-424 (2012) 154-161. doi:10.1016/j.apcata.2012.02.030.

[33] H. Zhang, Y.-T.-T. Cheng, T.P. Vispute, R. Xiao, G.W. Huber, Catalytic conversion of biomass-derived feedstocks into olefins and aromatics with ZSM-5: The hydrogen to carbon effective ratio, Energy Environ. Sci. 4 (2011) 2297-2307. doi:10.1039/c1ee01230d.

[34] K. Wang, K.H. Kim, R.C. Brown, Catalytic pyrolysis of individual components of lignocellulosic biomass, Green Chem. 16 (2014) 727. doi:10.1039/c3gc41288a.

[35] K. Wang, P.A. Johnston, R.C. Brown, Bioresource Technology Comparison of in-situ and ex-situ catalytic pyrolysis in a micro-reactor system, Bioresour. Technol. 173 (2014) 124-131. doi:10.1016/j.biortech.2014.09.097.

[36] H. Scott Fogler, Chemical reactors, in: Chem. React., Washington, D.C. : American Chemical Society, 1981.

http://www.essentialchemicalindustry.org/processes/chemical-reactors.html. 
[37] G. Zhou, P.A. Jensen, D.M. Le, N.O. Knudsen, A.D. Jensen, Direct upgrading of fast pyrolysis lignin vapor over the HZSM-5 catalyst, Green Chem. (2015). doi:10.1039/c5gc01976a.

[38] X. Zhu, R.G. Mallinson, D.E. Resasco, Role of transalkylation reactions in the conversion of anisole over HZSM-5, Appl. Catal. A Gen. 379 (2010) 172-181. doi:10.1016/j.apcata.2010.03.018.

[39] Jianbing Wu, High Si/Al ratio HZSM-5 zeolite: an efficient catalyst for the synthesis of polyoxymethylene dimethyl ethers from dimethoxymethane and trioxymethylene, Green Chem. 17 (2015) 2353-2357. doi:10.1039/b000000x.

[40] Z. Du, X. Ma, Y. Li, P. Chen, Y. Liu, X. Lin, H. Lei, R. Ruan, Production of aromatic hydrocarbons by catalytic pyrolysis of microalgae with zeolites: Catalyst screening in a pyroprobe, Bioresour. Technol. 139 (2013) 397-401. doi:10.1016/j.biortech.2013.04.053.

[41] S. Qu, G. Liu, F. Meng, L. Wang, X. Zhang, Catalytic Cracking of Supercritical n Dodecane over Wall-Coated HZSM-5 with Different Si/Al Ratios, Energy \& Fuels. 25 (2011) 2808-2814. doi:10.1021/ef2004706.

[42] C.D. Chang, Methanol Conversion to Light Olefins, Catal. Rev. 26 (1984) 323-345. doi:10.1080/01614948408064716.

[43] A.G. Gayubo, P.L. Benito, A.T. Aguayo, M. Olazar, J. Bilbao, Relationship between Surface Aciditv and Activity of catalysts in the Transforhation of Methanol into Hydrocarbons, J. Chem. Technol. Biotechnol. 65 (1996) 186-192.

[44] D.B. Luk'yanov, Effect of SiO2Al2O3 ratio on the activity of HZSM-5 zeolites in the different steps of methanol conversion to hydrocarbons, Zeolites. 12 (1992) 287-291. doi:10.1016/S0144-2449(05)80297-0. 
[45] C. Pan, J. Yu, Y. Zhou, Z. Wang, M.M. Zhou, An efficient method to synthesize benzofurans and naphthofurans, Synlett. 3 (2006) 1657-1662. doi:10.1055/s-2006944204.

488

489 
491 Table 1: Grouped yields of aromatic hydrocarbons and phenolic compounds (wt. \% of reactant)

\begin{tabular}{|c|c|c|c|c|c|c|c|c|}
\hline \multirow[b]{2}{*}{$\begin{array}{c}\mathrm{T} \\
\left({ }^{\circ} \mathrm{C}\right)\end{array}$} & \multirow[b]{2}{*}{ Catalyst } & \multirow[b]{2}{*}{$\begin{array}{c}\text { Anisole } \\
\text { Conversion } \\
(\%)\end{array}$} & \multirow[b]{2}{*}{$\begin{array}{c}\text { Aromatic } \\
\text { Hydrocarbons }\end{array}$} & \multicolumn{5}{|c|}{ Phenolic Compounds } \\
\hline & & & & Total & Phenol & $\begin{array}{c}0-\& \\
p \text {-cresol }\end{array}$ & Xylenols & $\begin{array}{c}\text { Trimethyl } \\
\text { phenols }\end{array}$ \\
\hline \multirow[t]{2}{*}{200} & $\begin{array}{l}\text { No } \\
\text { catalyst }\end{array}$ & 30.5 & 0.3 & 0.0 & 0.0 & 0.0 & 0.0 & 0.0 \\
\hline & $\mathrm{HZ}(25)$ & 73.6 & 0.0 & 27.4 & 18.3 & 6.8 & 2.1 & 0.2 \\
\hline \multirow[t]{2}{*}{300} & $\begin{array}{l}\text { No } \\
\text { catalyst }\end{array}$ & 38.2 & 0.4 & 0.0 & 0.0 & 0.0 & 0.0 & 0.0 \\
\hline & $\mathrm{HZ}(25)$ & 92.2 & 0.0 & 52.6 & 27.5 & 15.1 & 8.0 & 2.0 \\
\hline \multirow[t]{2}{*}{350} & $\mathrm{HZ}(25)$ & 98.0 & 0.8 & 60.6 & 27.9 & 18.7 & 10.8 & 3.2 \\
\hline & $\begin{array}{l}\text { No } \\
\text { catalyst }\end{array}$ & 39.8 & 0.7 & 0.0 & 0.0 & 0.0 & 0.0 & 0.0 \\
\hline \multirow{4}{*}{400} & $\mathrm{HZ}(25)$ & 99.4 & 1.9 & 70.0 & 28.6 & 24.3 & 13.8 & 3.3 \\
\hline & $\mathrm{HZ}(50)$ & 99.7 & 2.4 & 73.4 & 29.1 & 25.7 & 14.5 & 4.1 \\
\hline & $\mathrm{HZ}(80)$ & 99.5 & 0.3 & 78.9 & 30.1 & 27.2 & 17.1 & 4.5 \\
\hline & $\mathrm{HZ}(200)$ & 99.5 & 0.0 & 67.8 & 26.7 & 22.2 & 14.6 & 4.3 \\
\hline \multirow[t]{2}{*}{500} & $\begin{array}{l}\text { No } \\
\text { catalyst }\end{array}$ & 62.8 & 0.3 & 0.0 & 0.0 & 0.0 & 0.0 & 0.0 \\
\hline & $\mathrm{HZ}(25)$ & 100.0 & 31.2 & 10.0 & 5.7 & 4.3 & 0.0 & 0.0 \\
\hline 550 & $\begin{array}{l}\text { No } \\
\text { catalysts }\end{array}$ & 65.5 & 1.2 & 3.5 & 3.1 & 0.4 & 0.0 & 0.0 \\
\hline \multirow[t]{2}{*}{600} & $\begin{array}{l}\text { No } \\
\text { catalyst }\end{array}$ & 77.0 & 4.3 & 8.0 & 6.9 & 1.1 & 0.0 & 0.0 \\
\hline & $\mathrm{HZ}(25)$ & 100.0 & 33.5 & 0.0 & 0.0 & 0.0 & 0.0 & 0.0 \\
\hline 650 & $\begin{array}{l}\text { No } \\
\text { catalyst }\end{array}$ & 99.8 & 7.3 & 27.4 & 24.0 & 3.4 & 0.0 & 0.0 \\
\hline \multirow[t]{2}{*}{700} & $\begin{array}{l}\text { No } \\
\text { catalyst }\end{array}$ & 100.0 & 5.2 & 2.1 & 2.1 & 0.0 & 0.0 & 0.0 \\
\hline & $\mathrm{HZ}(25)$ & 100.0 & 27.6 & 0.0 & 0.0 & 0.0 & 0.0 & 0.0 \\
\hline \multirow[t]{2}{*}{800} & $\begin{array}{l}\text { No } \\
\text { catalyst }\end{array}$ & 100.0 & 4.9 & 1.1 & 1.1 & 0.0 & 0.0 & 0.0 \\
\hline & $\mathrm{HZ}(25)$ & 100.0 & 16.5 & 0.0 & 0.0 & 0.0 & 0.0 & 0.0 \\
\hline
\end{tabular}

492 
493

494 Table 2: Surface acidity of HZSM-5 zeolites with different Si/Al ratio as determined by Pyridine-FTIR analysis

\begin{tabular}{ccccccc}
\hline & \multicolumn{5}{c}{ Acid density (mmol of pyridine/g of zeolite) } \\
\cline { 2 - 7 } Si/Al ratio & total & weak & strong & total & weak & strong \\
\cline { 2 - 7 } 25 & 0.280 & 0.181 & 0.099 & 0.139 & 0.099 & 0.040 \\
50 & 0.237 & 0.148 & 0.089 & 0.076 & 0.056 & 0.020 \\
80 & 0.038 & 0.029 & 0.009 & 0.081 & 0.053 & 0.028 \\
200 & 0.041 & 0.033 & 0.008 & 0.051 & 0.037 & 0.014 \\
\hline
\end{tabular}

495

496

497 
500 Fig. 1 Schematic for reactor setup

501 Fig. 2 Influence of the presence of zeolite catalyst on the conversion of anisole at different reaction temperatures

Fig. 3 Yields of main products in the liquid fraction at different temperatures in (a) noncatalytic decomposition, and (b) catalytic decomposition over HZSM-5 [HZ(25)] of anisole; and, yield of methyl-phenols at different temperatures in (c) non-catalytic decomposition, and (d) catalytic decomposition over $\mathrm{HZ}(25)$

Fig. 4 Change of yields of carbonaceous deposit with: (a) temperature in non-catalytic decomposition and catalytic decomposition over $\mathrm{HZ}$ (25); and, (b) the Si/Al ratio in the zeolite for catalytic decomposition at $400{ }^{\circ} \mathrm{C}$

Fig. 5 Yield of (a) main products in the liquid fraction, and (b) multi-methyl phenols obtained over HZSM- 5 with Si/Al ratios of 25, 50, 80 and 200

Fig. 6 Reaction mechanisms for (a) catalytic (HZSM-5), and (b) non-catalytic transmethylation of anisole decomposition 


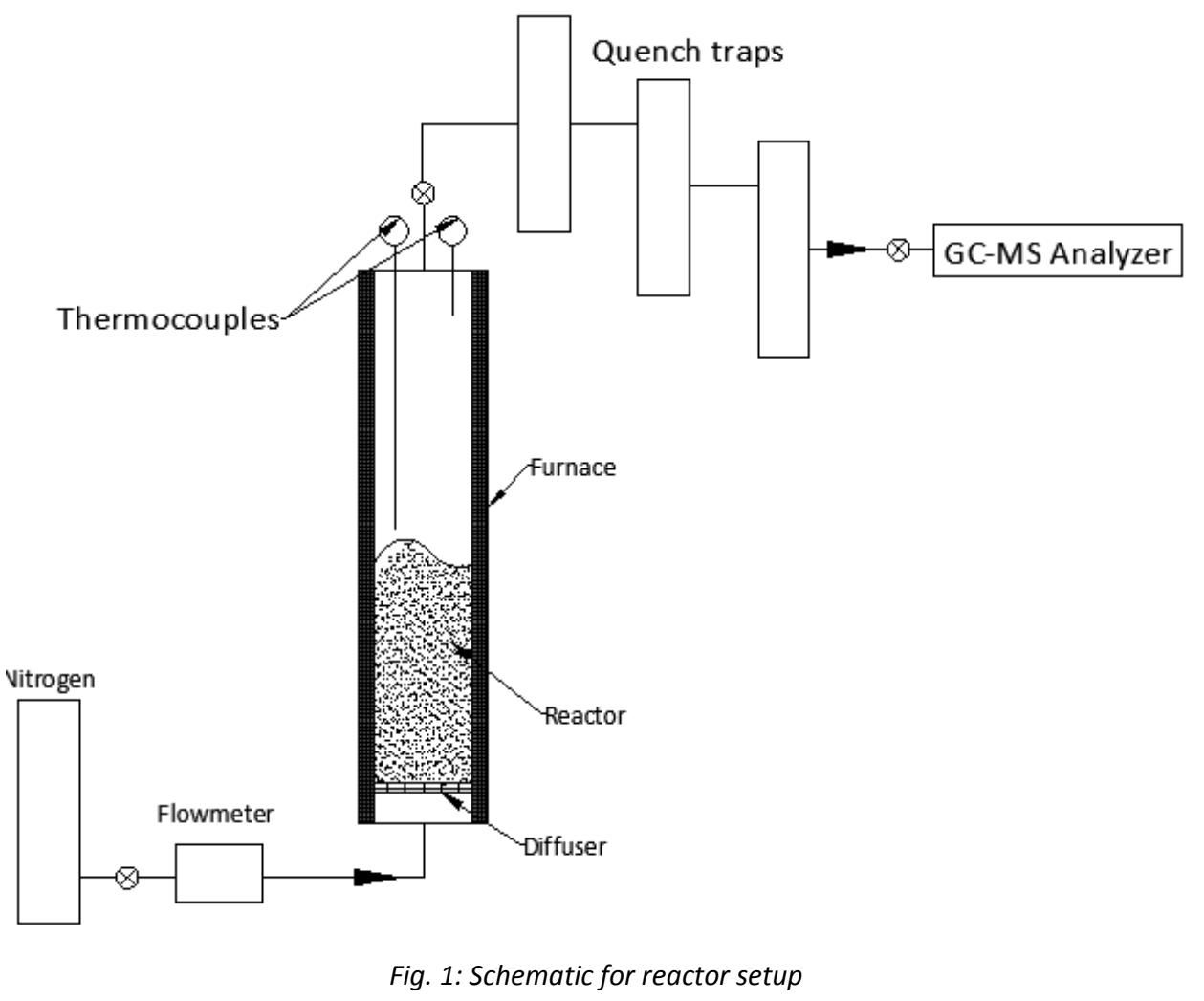

518 


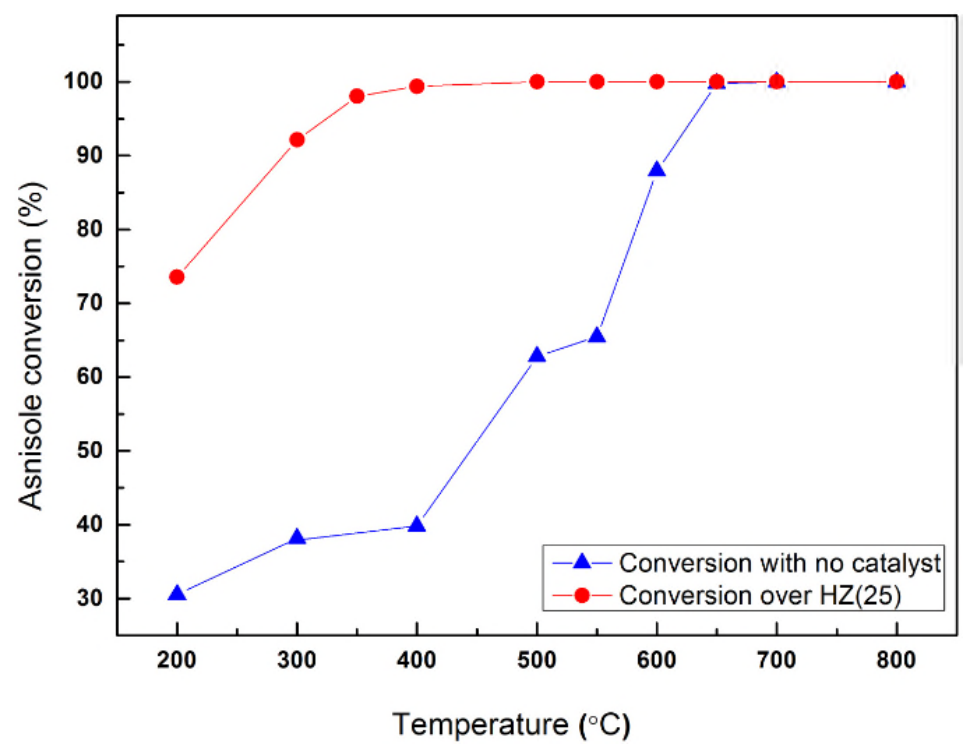

520

Fig. 2: Influence of the presence of zeolite catalyst on the conversion of anisole at different reaction temperatures

522 


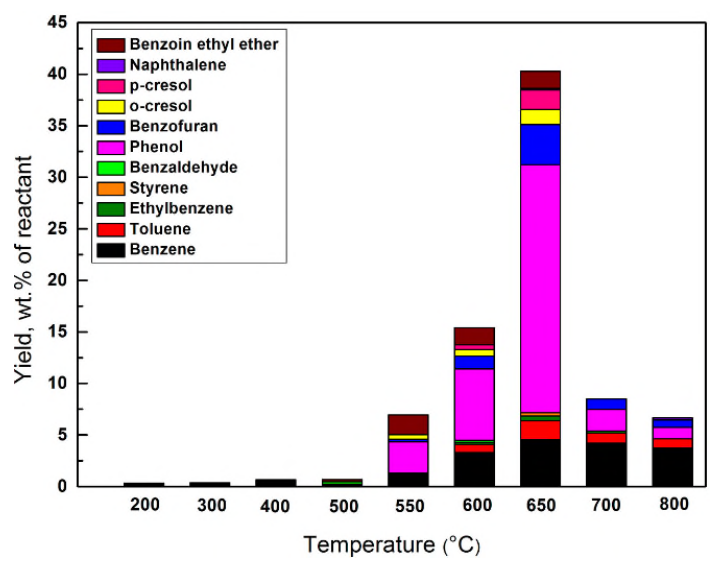

(a)

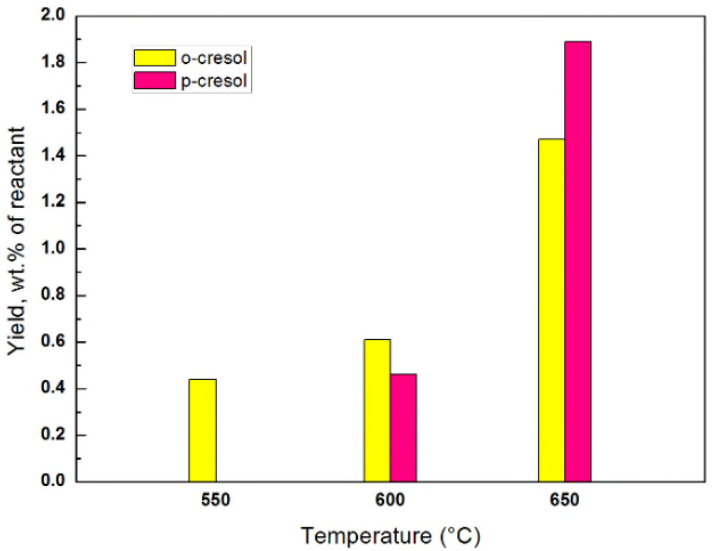

(c)

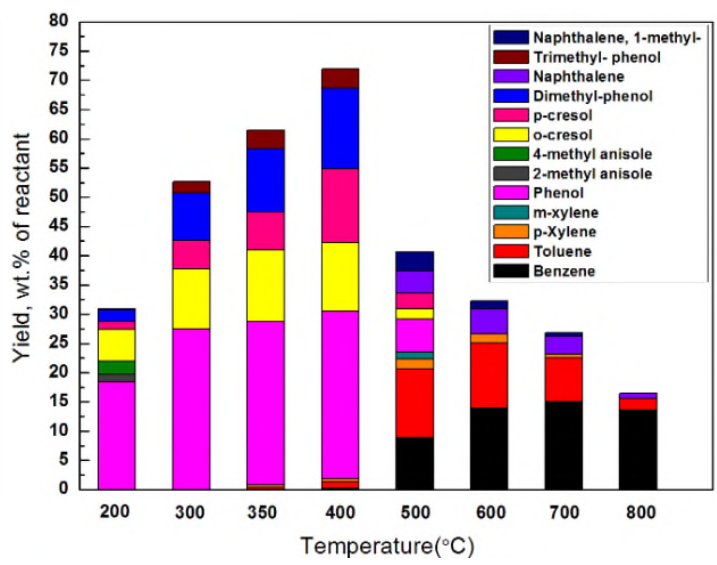

(b)

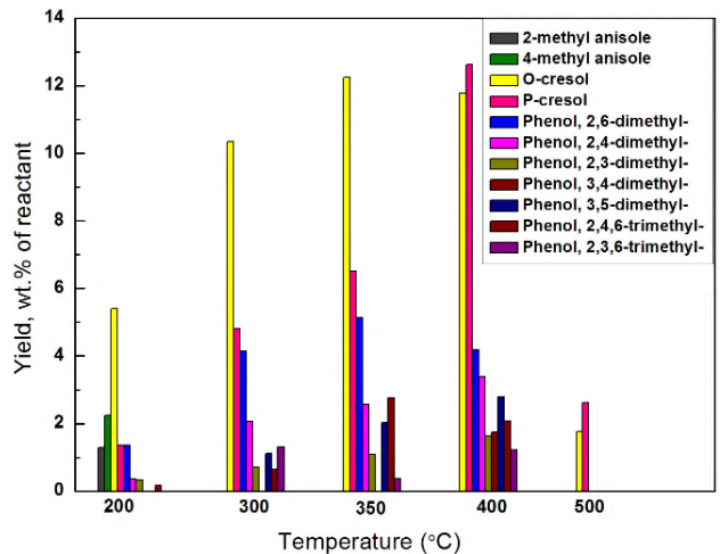

(d)

Fig. 3: Yields of main products in the liquid fraction at different temperatures in (a) non-catalytic decomposition, and (b) catalytic decomposition over HZSM-5 [HZ(25)] of anisole; and yield of methyl-phenols at different temperatures in (c) non-catalytic decomposition, and (d) catalytic decomposition over $\mathrm{HZ}(25)$ 

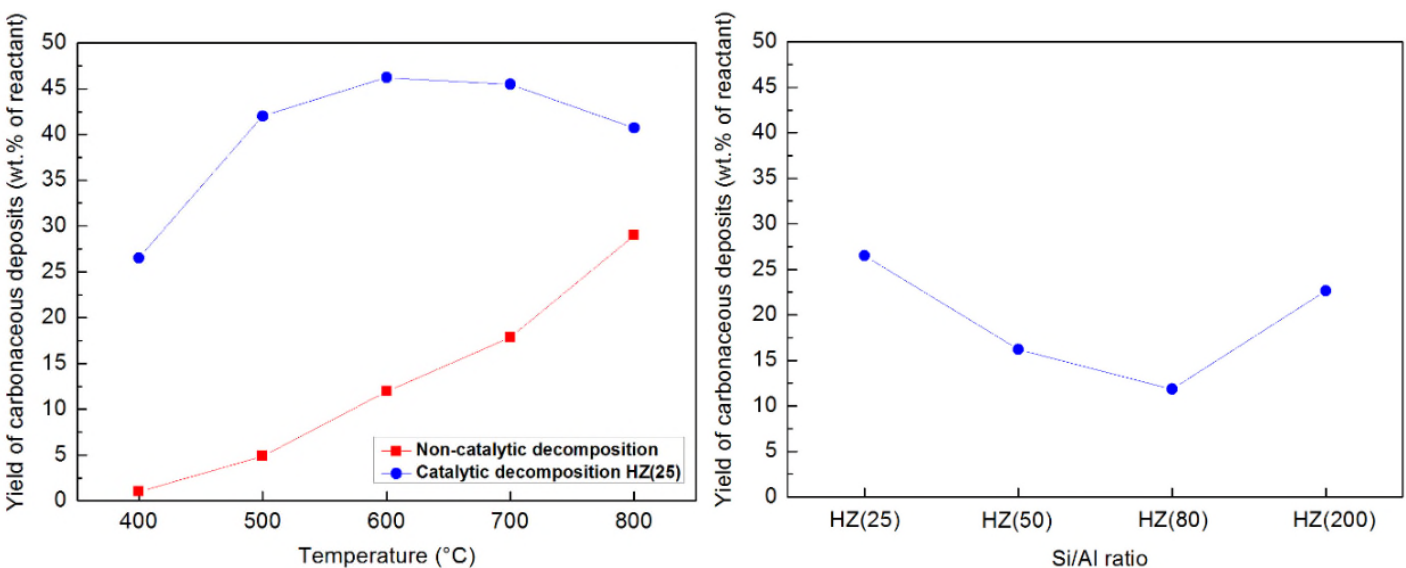

Fig. 4: Change of yields of carbonaceous deposit with: (a) temperature in non-catalytic decomposition and catalytic decomposition over $\mathrm{HZ} \mathrm{(25);} \mathrm{and,} \mathrm{(b)} \mathrm{the} \mathrm{Si/Al} \mathrm{ratio} \mathrm{in} \mathrm{the} \mathrm{zeolite} \mathrm{for} \mathrm{catalytic} \mathrm{decomposition} \mathrm{at} 400{ }^{\circ} \mathrm{C}$ 
538

539

540 541

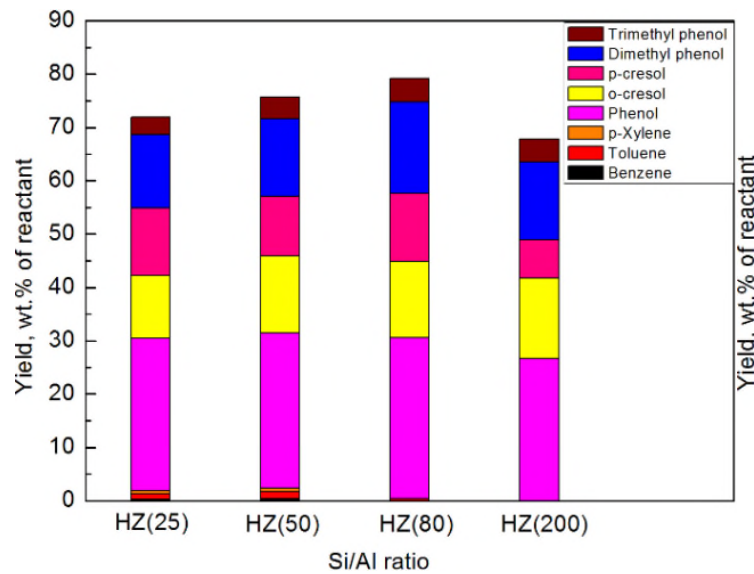

(a)

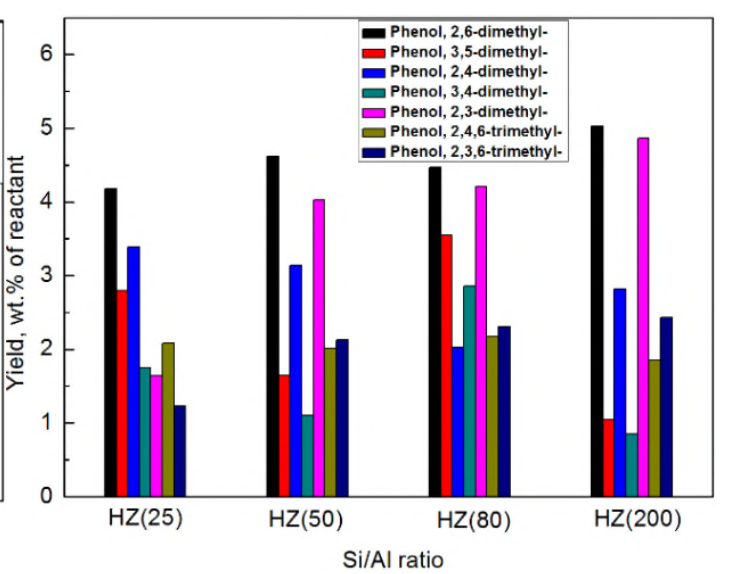

(b)

542

Fig. 5: Yield of (a) main products in the liquid fraction, and (b) multi-methyl phenols obtained over HZSM-5 with Si/Al ratios of 25, 50, 80 and 200 
544

545

546

548

549

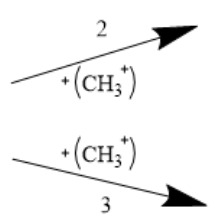<smiles>Cc1ccccc1O</smiles><smiles>Cc1ccc(O)cc1</smiles>

$\int$ $+\left(\mathrm{CH}_{3}{ }^{+}\right)$
4

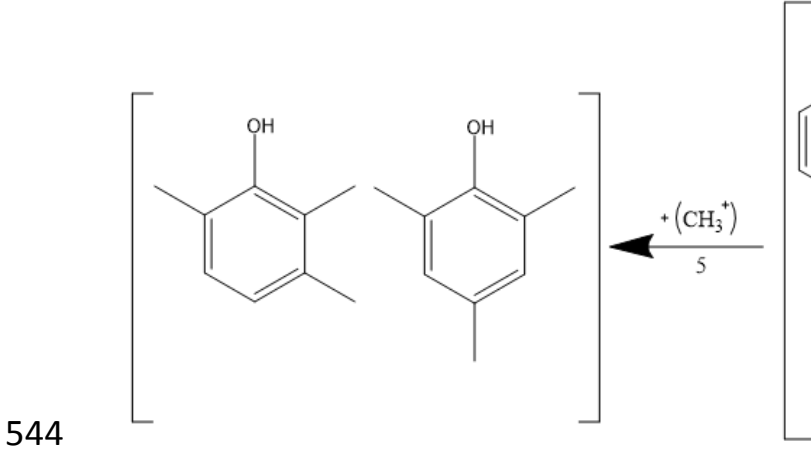<smiles>C/C=C\C=C/C</smiles><smiles>CCc1cccc(C)c1O</smiles>

(a)<smiles>COc1ccccc1C(C)(C)c1ccc(O)cc1</smiles><smiles>[R]c1ccccc1O[C@H](C)C(C)(C)C(C)(C)C</smiles><smiles>c1ccc2occc2c1</smiles><smiles>CC1=CCCC[C-]1C</smiles>

Deoxygenation

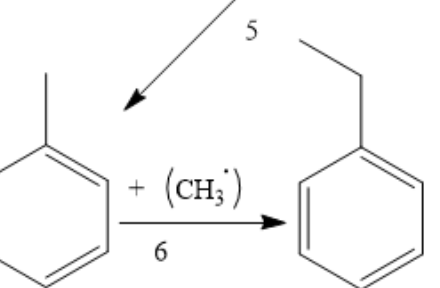

(b)

Fig. 6: Reaction mechanism for (a) catalytic (HZSM-5), and (b) non-catalytic transmethylation of anisole decomposition 


\section{Supplementary material}

Table S1: Peak area and relative percentage of the identified products based on the results of gas chromatograph-mass spectrometer for non-catalytic decomposition of anisole at $650^{\circ} \mathrm{C}$

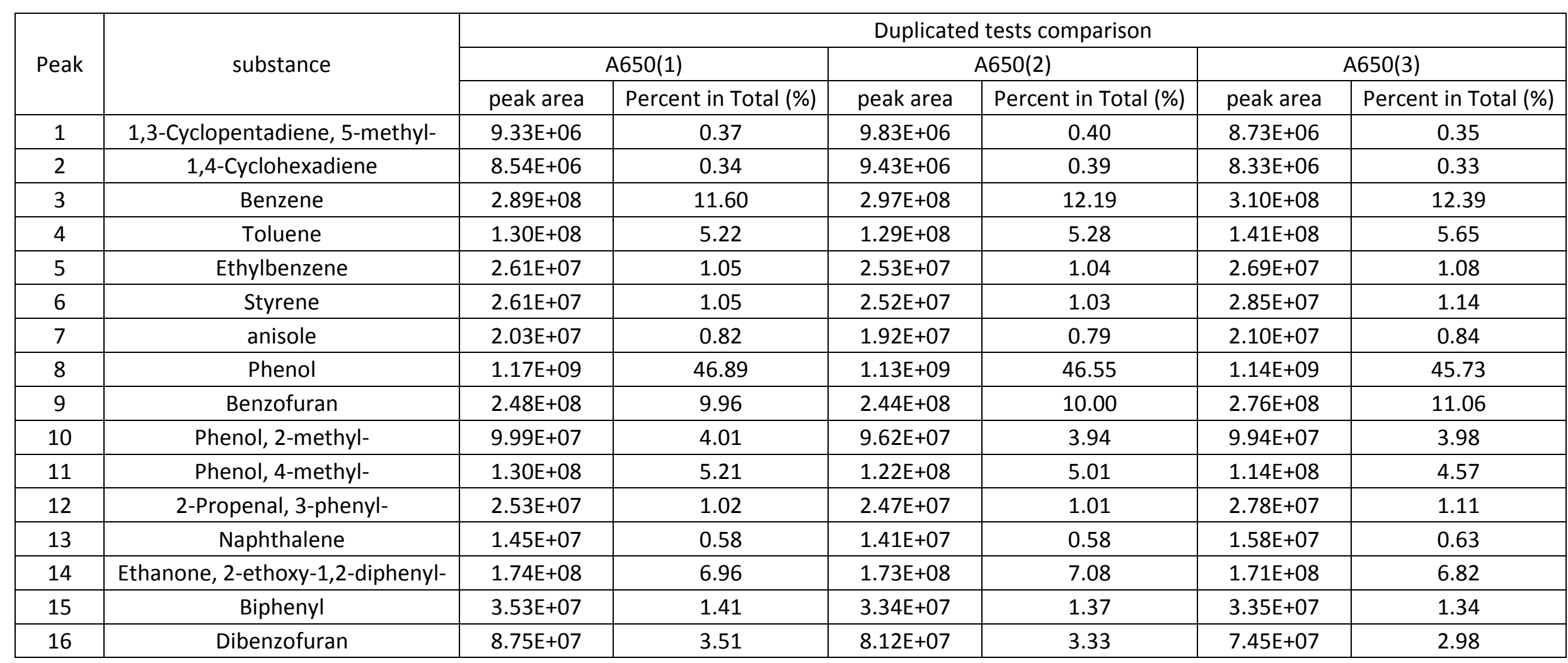


Table S2: Deviation analysis for the duplication tests of non-catalytic decomposition of anisole at $650^{\circ} \mathrm{C}$

\begin{tabular}{|c|c|c|c|c|c|c|c|}
\hline \multirow{3}{*}{ Peak } & \multirow{3}{*}{ substance } & \multicolumn{6}{|c|}{ Duplicated tests comparison } \\
\hline & & \multicolumn{2}{|c|}{ A650(1) } & \multicolumn{2}{|c|}{$\mathrm{A} 650(2)$} & \multicolumn{2}{|c|}{ A650(3) } \\
\hline & & peak area & Percent in Total (\%) & peak area & Percent in Total (\%) & peak area & Percent in Total (\%) \\
\hline 1 & 1,3-Cyclopentadiene, 5-methyl- & 0.39 & -0.33 & 5.69 & 7.32 & -6.08 & -0.33 \\
\hline 3 & Benzene & -3.16 & -3.80 & -0.48 & 1.11 & 3.64 & -3.80 \\
\hline 4 & Toluene & -2.39 & -3.01 & -3.50 & -1.93 & 5.88 & -3.01 \\
\hline 5 & Ethylbenzene & -0.08 & -0.72 & -3.02 & -1.45 & 3.09 & -0.72 \\
\hline 7 & anisole & 0.72 & 0.09 & -4.89 & -3.34 & 4.16 & 0.09 \\
\hline 8 & Phenol & 1.75 & 1.08 & -1.23 & 0.35 & -0.52 & 1.08 \\
\hline 9 & Benzofuran & -3.06 & -3.67 & -4.84 & -3.29 & 7.90 & -3.67 \\
\hline 10 & Phenol, 2-methyl- & 1.43 & 0.77 & -2.36 & -0.79 & 0.93 & 0.77 \\
\hline 11 & Phenol, 4-methyl- & 6.37 & 5.66 & 0.03 & 1.61 & -6.40 & 5.66 \\
\hline 12 & 2-Propenal, 3-phenyl- & -2.36 & -2.97 & -4.84 & -3.28 & 7.20 & -2.97 \\
\hline 16 & Dibenzofuran & 7.99 & 7.26 & 0.12 & 1.70 & -8.11 & 7.26 \\
\hline
\end{tabular}

Notes:

1)* Deviation $=100 \% \times$ (eigenvalue - average value)/average value

2)* Deviation were all within $10 \%$, and most of them were within $5 \%$. Deviations more than $5 \%$ have been highlighted

3)* Apart from this set, other sets of experiment were all implemented twice 